\title{
EDITORIAL
}

\section{Modeling and Simulation of Infectious Diseases}

\author{
Tarek I. Zohdi ${ }^{1}$
}

Published online: 8 July 2021

(c) CIMNE, Barcelona, Spain 2021

The COVID19 pandemic of 2020 has been responsible for millions of deaths. It is undoubtedly the most critical health issue that modern civilization has ever faced.

This special issue collects works in the area of modeling and simulation of infectious diseases from leading researchers in computational science and engineering.
We hope that this research will provide insight, spark discussion, and help shape a way towards solving this public health problem that continues to challenge humanity.

Publisher's Note Springer Nature remains neutral with regard to jurisdictional claims in published maps and institutional affiliations.

Tarek I. Zohdi

zohdi@berkeley.edu

http://www.me.berkeley.edu/people/faculty/tarek-i-zohdi

https://msol.berkeley.edu/

1 Department of Mechanical Engineering, UC Berkeley, 6117

Etcheverry Hall, UC, Berkeley, CA 94720-1740, USA 